\title{
Perioperative clinical parameters associated with short-term mortality after colorectal perforation
}

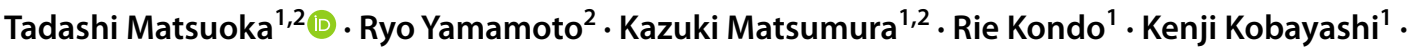 \\ Alan Kawarai Lefor ${ }^{3} \cdot$ Junichi Sasaki $^{2} \cdot$ Hiroharu Shinozaki ${ }^{1}$
}

Received: 16 July 2020 / Accepted: 27 May 2021 / Published online: 3 June 2021

(c) Springer-Verlag GmbH Germany, part of Springer Nature 2021

\begin{abstract}
Purpose Although early prediction of mortality is useful for the management of patients with colorectal perforations, no significant perioperative predictive factors have been identified. The purpose of this study was to identify useful prognostic factors for patients with colorectal perforation.

Methods This single-center retrospective study included consecutive patients undergoing emergency surgery for colorectal perforation from January 2012 to December 2019. The primary outcome was combined 30 day and in-hospital mortality. Patient- and disease-related factors obtained perioperatively were evaluated for mortality prediction. A scoring system was developed to enhance clinical utility.

Results Overall, 146 patients were included and 20 (14\%) died after surgery. Multivariate logistic regression identified five predictive factors: age, hemodialysis, uncommon perforation etiology, plasma albumin level, and decreased platelet count. The area under the receiver operating curve for the scoring system using these parameters was 0.894 (95\% CI 0.835-0.952). Patients at high-risk of mortality were classified by the proposed score with a sensitivity of $90.0 \%$ and negative predictive value of $98.0 \%$.

Conclusion This study identified five perioperative factors significantly associated with mortality of patients with colorectal perforation. Although these parameters predict mortality of patients with colorectal perforation using a score with high discrimination, further study is required to confirm these findings.
\end{abstract}

Keywords Colorectal perforation $\cdot$ Emergency surgery $\cdot$ Prognostic predictors $\cdot$ Coagulopathy

\section{Background}

Colorectal perforation, which frequently leads to sepsis or septic shock, continues to be associated with high mortality [1-4]. Patients who do survive a colorectal perforation often need prolonged hospitalization with greater cost and impaired ability to manage activities of daily living, which makes it difficult to return to normal life $[1,4,5]$. Sepsis may

Tadashi Matsuoka

tadashi_matsuoka1984@yahoo.co.jp

1 Department of Surgery, Saiseikai Utsunomiya Hospital, 911-1 Takebayashi-cho, Utsunomiya, Tochigi 321-0974, Japan

2 Department of Emergency and Critical Care Medicine, School of Medicine, Keio University, Shinjuku, Tokyo, Japan

3 Department of Surgery, Jichi Medical University, Shimotsuke, Tochigi, Japan cause coagulopathy and is related to a poor prognosis [6-8]. Patients with colorectal perforation and fecal peritonitis may develop coagulopathy, which is linked with higher mortality and morbidity [8-10]. Therefore, findings of coagulopathy, such as thrombocytopenia or prolongation of prothrombin time in patients with colorectal perforation may be important to improve overall outcomes.

While several prognostic factors for colorectal perforation were investigated, including age, etiology of perforation, coagulopathy, and physiological disturbance, few studies focus on the host response to inflammation and/or surgical stress, which influence postoperative management. As physiological changes, such as worsening coagulopathy, may reflect the severity of disease, clinical parameters should be examined considering perioperative physiology. Although some scoring systems, including POSSUM and the Mannheim peritonitis index, utilize multiple prognostic factors to enhance mortality prediction, they target only left sided 
colorectal perforations and need complicated calculations which limit their practical application. Other scoring systems that can be used to classify critically ill patients, such as APACHE II and SOFA, were not developed to assess the severity of colorectal perforation, and it has not been clarified whether these scores, or factors in the scores, are associated with the prognosis of patients with colorectal perforations.

Elucidating the factors that influence the mortality and morbidity of patients with colorectal perforation is of great importance to surgeons who perform emergency surgery for patients with colorectal perforation. Clinical factors that can be obtained immediately before and after surgery must be examined in detail, and an accurate and easy-to-use scoring system should be eventually developed. The purpose of this study was to identify clinically relevant prognostic factors for patients with colorectal perforation and to propose a candidate scoring system to be validated in future studies.

\section{Methods}

\section{Study design}

This retrospective study was approved by the Institutional Review Board of Saiseikai Utsunomiya Hospital (No.2020). Consecutive patients undergoing emergency surgery for colorectal perforation from January 2012 to December 2019 at Saiseikai Utsunomiya Hospital in Tochigi, Japan were included in this study. The diagnosis of colorectal perforation in these patients was based on computed tomography (CT) scan findings and confirmed by operative findings. The etiology of colorectal perforation was based on intraoperative and pathological findings. Emergency surgery was defined as an operation performed within $24 \mathrm{~h}$ after making the diagnosis. Patients with colorectal perforation due to traumatic or iatrogenic injury, and limitations of care were also excluded. Patients diagnosed preoperatively with a colorectal perforation but found to have an upper gastrointestinal perforation intraoperatively, or patients with a perforation site not identified intraoperatively were excluded. The primary outcome of this study was the combined 30-day and in-hospital mortality. Patients who died in the hospital at any time after the operation were included, as well as all patients who died within 30 days of the initial operation regardless of whether they were in the hospital or not. The secondary outcome was the rate of major postoperative complications. Major postoperative complications included cardiovascular dysfunction, respiratory dysfunction, and coagulopathy. Cardiovascular dysfunction was defined as a requirement for vasopressors (noradrenalin of $0.2 \mu \mathrm{g} / \mathrm{kg} / \mathrm{min}$ and/or vasopressin). Respiratory dysfunction was defined as the need for postoperative mechanical ventilation for 7 days or more.
Coagulopathy was characterized by (1) an INR greater than 1.40 without a known etiology (e.g. anticoagulant therapy, chronic liver disease), (2) platelet count less than $150 \times 10^{9} / \mathrm{L}$ or a decrease in platelet count greater than $25 \%$ immediate after operation and (3) the perioperative need for transfusion of more than 10 units of fresh frozen plasma.

\section{Data collection}

Clinical and demographic data for study patients were abstracted from the medical records. The etiology of the perforation was based on CT scan and operative findings and confirmed by pathological findings. Postoperative laboratory data were defined as data measured immediately after operation in the ICU or inpatient ward, not routine data obtained on postoperative day 1 . Perioperative changes in white blood cell count, platelet count, and PT-INR were determined by comparing preoperative and postoperative values. In the SOFA and APACHE II Scores, the worst score from admission to $24 \mathrm{~h}$ after operation is used.

\section{Statistical analysis}

All variables are expressed as the median (interquartile range [IQR]) or proportions. Baseline characteristics were compared between the "survived" and "died" groups using the Mann-Whitney $U$ test and Fisher's exact test.

To identify factors significantly associated with colorectal perforation, a multivariate logistic regression model was developed using the backward stepwise method, in which continuous outcomes were dichotomized based on previous studies. Precision of the logistic model was determined with area under the receiver operating characteristic curve (AUC) for mortality prediction calculated using original samples, bootstrap resampling, and stratified tenfold crossvalidation. Variables in the regression model were assessed for co-linearity using the variance inflation factor, in which a value less than ten indicates a lack of multicollinearity. Factors with a $p$ value $<0.05$ were considered to be statistically significant for mortality in colorectal perforation. Factors with $\mathrm{p}$ value $<0.10$ were also considered as non-negligible prognostic factors to avoid overlooking significant prognostic factors due to small sample size and lack of power. The identified prognostic factors were then similarly examined regarding whether they would predict the secondary outcome, the incidence of major postoperative complications.

To enhance the clinical utility of the identified prognostic factors, a scoring system was proposed, with point scores assigned to the identified predictors based on the risk estimate in the logistic model. The AUC of the score for mortality prediction was calculated and compared with SOFA and APACHE II Scores. Classification of patients at high risk of mortality based on the score was also assessed. 
Missing data were analyzed without imputation or manipulation. All data were analyzed using SPSS 26.0 statistical software (SPSS Inc., Chicago, IL) and R version 4.0.0 (R Foundation for Statistical Computing, Vienna, Austria).

\section{Results}

\section{Patients}

During the study period, 167 patients underwent emergency surgery for colorectal perforation. After applying exclusion criteria (21 patients), 146 patients were analyzed. Of these, 20/146 patients (13.7\%) died in the hospital postoperatively (Fig. 1). No patients died between discharge and postoperative day 30. Patient characteristics are shown in Table 1. Patients who died were significantly older compared with those who survived. The time interval from onset of symptoms to surgery was shorter in patients who died compared with those who survived. There was no significant difference between the two groups in the incidence of comorbidities or the rate of hypotension at diagnosis. There were two patients with missing data: one patient with no data for PT-INR and SOFA Score, one with no data for PT-INR.

\section{Disease and operative findings}

Disease and operative findings are shown in Table 2. There were significant differences in the distribution of perforation etiologies or sites. Patients who died were more likely to have etiologies other than diverticulitis or cancer, such as ischemia and fecal impaction, and patients who survived were more likely to have diverticulitis. The sigmoid colon was a more common site of perforation among those who
Table 1 Patient characteristics

\begin{tabular}{|c|c|c|c|}
\hline & $\begin{array}{l}\text { Died } \\
(N=20)\end{array}$ & $\begin{array}{l}\text { Survived } \\
(N=126)\end{array}$ & $p$ value \\
\hline Age (years) & $83(89-77)$ & $71(81-61)$ & 0.005 \\
\hline Male $N(\%)$ & $9(45)$ & $67(53)$ & 0.631 \\
\hline $\begin{array}{l}\text { Body mass index }(\mathrm{kg} / \\
\left.\mathrm{m}^{2}\right)\end{array}$ & $19.5(23.4-19.1)$ & $21.5(24.2-19.4)$ & 0.169 \\
\hline \multicolumn{4}{|l|}{ Comorbidities } \\
\hline Hypertension & $12(60)$ & $54(43)$ & 0.226 \\
\hline Diabetes mellitus & $3(15)$ & $13(10)$ & 0.462 \\
\hline $\begin{array}{l}\text { Coronary artery } \\
\text { disease }\end{array}$ & $1(5)$ & $10(8)$ & 1.000 \\
\hline $\begin{array}{l}\text { Cerebrovascular } \\
\text { disease }\end{array}$ & $2(10)$ & $8(6)$ & 0.628 \\
\hline Atrial fibrillation & $4(20)$ & $9(7)$ & 0.081 \\
\hline $\begin{array}{l}\text { Chronic kidney } \\
\text { disease with hemo- } \\
\text { dialysis }\end{array}$ & $3(15)$ & $7(6)$ & 0.140 \\
\hline Malignancy $^{\mathrm{a}}$ & $3(15)$ & $16(13)$ & 0.726 \\
\hline $\begin{array}{l}\text { Immunocompro- } \\
\text { mised state }\end{array}$ & $4(20)$ & $16(13)$ & 0.480 \\
\hline \multicolumn{4}{|l|}{ Time (hours) ${ }^{\mathrm{b}}$} \\
\hline Onset to surgery & $8(23-3)$ & $13(45-3)$ & 0.001 \\
\hline Onset to diagnosis & $4(8-0)$ & $9(28-0)$ & 0.089 \\
\hline Diagnosis to surgery & $3(8-2)$ & $4(5-2)$ & 0.695 \\
\hline $\begin{array}{l}\text { Hypotension at diag- } \\
\text { nosis }\end{array}$ & $5(25)$ & $14(12.5)$ & 0.142 \\
\hline
\end{tabular}

Values are expressed as the median (interquartile) or the number (percent)

${ }^{\text {a }}$ Patients with perforated tumors are not included

' Time of onset was based on the patients' complaint; the time of diagnosis was defined as the time of consultation with the surgeon; the time of surgery was defined as the time of starting surgery

Fig. 1 Study flowchart

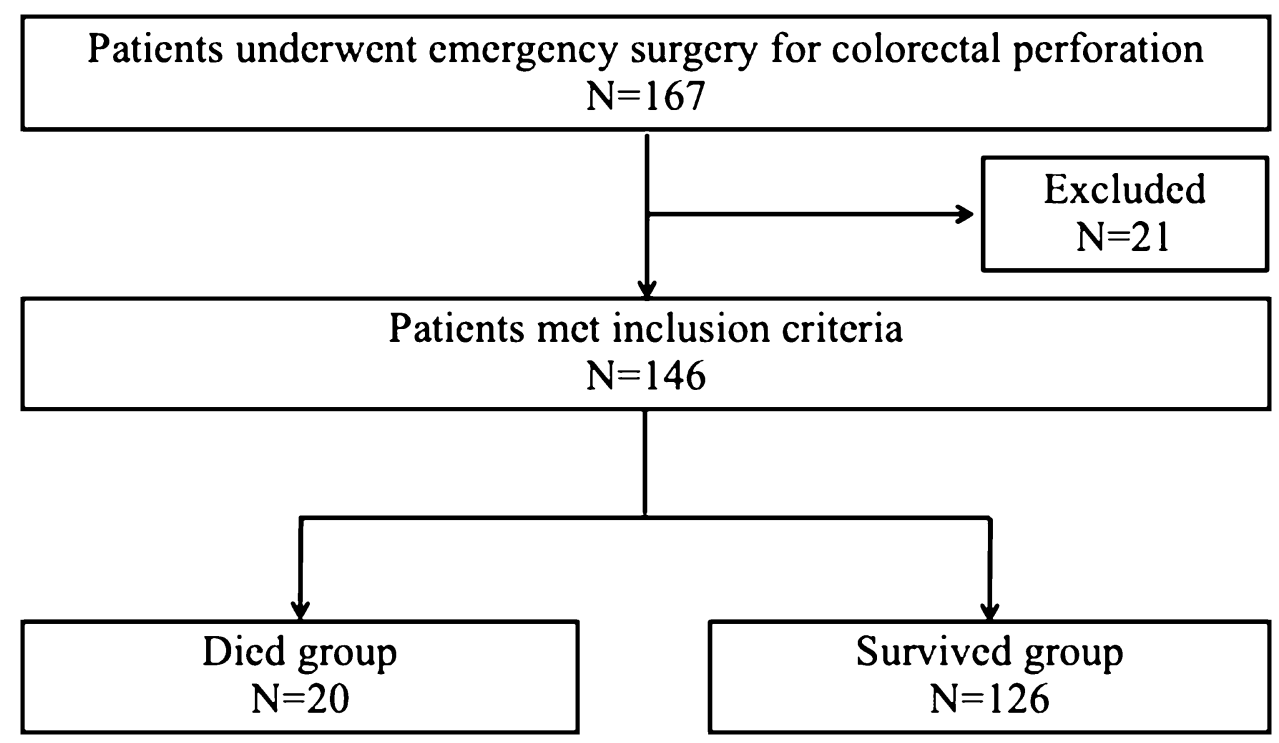


Table 2 Disease and operative characteristics

\begin{tabular}{|c|c|c|c|}
\hline & $\begin{array}{l}\text { Died } \\
(N=20)\end{array}$ & $\begin{array}{l}\text { Survived } \\
(N=126)\end{array}$ & $p$ value \\
\hline Etiology of perforation (\%) & & & 0.034 \\
\hline Diverticulitis $^{\mathrm{a}}$ & $5(25)$ & $69(55)$ & \\
\hline Cancer & $6(30)$ & $34(25)$ & \\
\hline Uncommon others $^{\mathrm{a}}$ & $9(45)$ & $23(20)$ & \\
\hline Fecal impaction & $6(30)$ & $11(11)$ & \\
\hline Ischemia & $2(10)$ & $5(4)$ & \\
\hline Idiopathic & $1(5)$ & $4(3)$ & \\
\hline Site of perforation (\%) & & & 0.017 \\
\hline Cecum/ascending colon & $1(5)$ & $11(9)$ & \\
\hline Transverse colon ${ }^{\mathrm{a}}$ & $2(10)$ & $2(2)$ & \\
\hline Descending colon & $3(15)$ & $6(5)$ & \\
\hline Sigmoid colon $^{\mathrm{a}}$ & $6(30)$ & $76(60)$ & \\
\hline Rectum & $8(40)$ & $31(24)$ & \\
\hline Type of surgery (\%) & & & 0.057 \\
\hline Resection, stoma formation & $19(95)$ & $117(92)$ & \\
\hline Resection, anastomosis & $0(0)$ & $3(2)$ & \\
\hline Stoma formation & $1(5)$ & $0(0)$ & \\
\hline Others & $0(0)$ & $5(4)$ & \\
\hline Hinchey classification (\%) & & & 0.673 \\
\hline I & $3(15)$ & $30(24)$ & \\
\hline II & $1(5)$ & $7(6)$ & \\
\hline III & $4(20)$ & $31(25)$ & \\
\hline IV & $12(60)$ & $57(45)$ & \\
\hline Operating time $(\min )$ & $142(183-101)$ & $155(190-121)$ & 0.524 \\
\hline Estimated blood loss (ml) & $290(537-44)$ & $200(358-43)$ & 0.349 \\
\hline Intraoperative fluid administration (1) & $3.3(4.6-2.3)$ & $2.6(3.6-2.0)$ & 0.086 \\
\hline Intraoperative fluid balance (1) & $2.7(3.1-1.1)$ & $1.9(2.6-1.4)$ & 0.166 \\
\hline
\end{tabular}

Values are expressed as the median (interquartile) or the number (percent)

${ }^{\text {a }}$ Statistically significant difference as determined by post hoc analysis and Fisher's exact test survived. There were no significant differences in the type of operation, Hinchey classification, operating time or estimated blood loss.

\section{Laboratory studies}

Laboratory studies are shown in Table 3. At diagnosis, there were no significant differences in white blood cell count, platelet count, or prothrombin time between the two groups. However, the serum albumin level was lower among those who died. Postoperatively, the white blood cell and platelet counts were significantly lower in patients who died. The postoperative decrease in these parameters from the time of diagnosis was significantly greater in those who died.

\section{Postoperative outcomes}

Postoperative outcomes are shown in Table 4. Although the rate of sepsis was comparable between the two groups, the rate of septic shock was higher among those who died. The APACHE II and SOFA Scores were significantly higher in those who died. The number of ventilator days and ICU length of stay were significantly longer for those who died. Hospital length of stay was similar in the two groups.

\section{Perioperative clinical parameters associated with mortality}

Multivariate analysis identified five variables that were significantly related to mortality in patients after colorectal perforation: age, comorbidity of hemodialysis, plasma albumin level, uncommon etiology of perforation, and decrease in the platelet count (Table 5). A decrease in platelet count and age were strongly related with in-hospital mortality in patients after colorectal perforation. All variables had a variance inflation factor of less than 1.1, which means there was no multicollinearity between the predictors. Age, plasma albumin level, and decrease in the 
Table 3 Laboratory data

\begin{tabular}{lllr}
\hline & $\begin{array}{l}\text { Died } \\
(N=20)\end{array}$ & $\begin{array}{l}\text { Survived } \\
(N=126)\end{array}$ & $p$ value \\
\hline At diagnosis & & & \\
$\quad$ White blood cell count $\left(\times 10^{3} / \mu \mathrm{L}\right)$ & $6.0(10.2-1.8)$ & $9.7(13.9-5.6)$ & 0.138 \\
Platelet count $\left(\times 10^{4} / \mu \mathrm{L}\right)$ & $24.0(31.6-16.5)$ & $23.1(30.3-15.9)$ & 0.896 \\
Prothrombin time $(\mathrm{INR})$ & $1.05(1.16-0.94)$ & $1.09(1.19-0.99)$ & 0.796 \\
Albumin $(\mathrm{g} / \mathrm{dL})$ & $2.6(3.2-2.0)$ & $3.3(3.9-2.7)$ & 0.009 \\
Postoperative & & & 0.006 \\
White blood cell count $\left(\times 10^{3} / \mu \mathrm{L}\right)$ & $3.2(6.5-0.1)$ & $8.6(14.1-3.2)$ & 0.028 \\
Decrease from diagnosis $(\%)$ & $42.4(67.6-17.2)$ & $12.5(40.2-15)$ & 0.035 \\
Platelet count $\left(\times 10^{4} / \mu \mathrm{L}\right)$ & $14.5(18.2-10.8)$ & $18.2(24.1-12.4)$ & $<0.001$ \\
Decrease from diagnosis $(\%)$ & $39.3(49.9-28.6)$ & $15.1(26.9-3.2)$ & 0.288 \\
Prothrombin time $(\mathrm{INR})$ & $1.28(1.62-1.13)$ & $1.24(1.44-1.10)$ & \\
\hline
\end{tabular}

Values are expressed as the median (interquartile) or the number (percent)

Table 4 Postoperative outcomes

\begin{tabular}{|c|c|c|c|}
\hline & $\begin{array}{l}\text { Died } \\
(N=20)\end{array}$ & $\begin{array}{l}\text { Survived } \\
(N=126)\end{array}$ & $p$ value \\
\hline $\begin{array}{l}\text { Major postoperative complica- } \\
\text { tions }\end{array}$ & $16(80)$ & $27(21)$ & $<0.001$ \\
\hline Cardiovascular dysfunction & $9(45)$ & $12(10)$ & $<0.001$ \\
\hline Respiratory dysfunction & $9(45)$ & $10(8)$ & $<0.001$ \\
\hline Coagulopathy & $16(80)$ & $27(21)$ & $<0.001$ \\
\hline \multicolumn{4}{|l|}{ Severity } \\
\hline APACHE II Score & $19(25-14)$ & $13(18-9)$ & $<0.001$ \\
\hline SOFA Score & $10(13-7)$ & $4(7-3)$ & $<0.001$ \\
\hline Ventilator days & $10(16-4)$ & $0(2-0)$ & $<0.001$ \\
\hline Intensive care unit length of stay & $12(20-5)$ & $3(6-1)$ & $<0.001$ \\
\hline Hospital Length of stay & $29(45-12)$ & $24(34-14)$ & 0.480 \\
\hline
\end{tabular}

Values are expressed as the median (interquartile) or the number (percent)

APACHE II acute physiology and chronic health evaluation II, SOFA sequential organ failure assessment

platelet count were also identified to predict the occurrence of major postoperative complications. The AUC of the logistic model for mortality prediction was 0.911 (95\% CI 0.852-0.970), and corrected AUC was 0.881 in bootstrapping resampling and 0.878 in stratified tenfold cross-validation.

A 0-10 score was proposed using the five prognostic factors (Table 6), and the AUC was calculated as 0.903 (95\% CI 0.840-0.965, while those of SOFA and APACHE II were 0.803 and 0.764 , respectively (Fig. 2). Patients with high risk of mortality (estimated mortality $>25 \%$, the Score $\geq 5$ points) were classified by the proposed score with a sensitivity of $90.0 \%$ and a negative predictive value (NPV) of $98.0 \%$ (Supplemental Table 1). The AUC of the score for predicting the development of major postoperative complications was 0.776 (95\% CI, 0.694-0.859).

\section{Discussion}

In this study, we identified five perioperative clinical parameters associated with short-term mortality following colorectal perforation. Notably, one of the prognostic factors was a decrease in the platelet count, which may reflect worsening coagulopathy as a response to inflammation and/or surgical stress. The value of these five simple predictors can be easily obtained without additional tests immediately before or after surgery, which may facilitate clinical utility. A scoring
Table 5 Selected predictive variables for a multivariable model of mortality

\begin{tabular}{|c|c|c|c|c|c|}
\hline \multirow[b]{2}{*}{ Age, (years) } & \multirow{2}{*}{$\begin{array}{l}\text { Coefficient } \\
0.07\end{array}$} & \multirow{2}{*}{$\begin{array}{l}\text { Wald } \\
5.33\end{array}$} & \multicolumn{2}{|c|}{ Odds ratio $(95 \% \mathrm{CI})$} & \multirow{2}{*}{$\begin{array}{l}p \text { value } \\
0.021\end{array}$} \\
\hline & & & 1.07 & $1.01-1.13$ & \\
\hline Comorbidity of hemodialysis & 2.46 & 6.03 & 11.7 & $1.65-83.89$ & 0.014 \\
\hline Albumin, $(\mathrm{g} / \mathrm{dL})$ & -0.65 & 3.12 & 0.52 & $0.26-1.07$ & 0.078 \\
\hline $\begin{array}{l}\text { Uncommon etiology (other than diver- } \\
\text { ticulitis, cancer) }\end{array}$ & 1.41 & 5.38 & 4.11 & $1.24-13.57$ & 0.020 \\
\hline Reduction of platelet count $\geqq 25(\%)$ & -0.06 & 10.82 & 0.94 & $0.91-0.98$ & 0.001 \\
\hline
\end{tabular}

Omnibus tests of model coefficients: $p<0.001, R$ square $=0.486$

Wald Wald statics, 95\% CI 95\% confidential interval. 
Table 6 Scoring system based on predictive factors for mortality

\section{Points Odds ratio $(95 \% \mathrm{CI})$}

Comorbidity of hemodialysis

\begin{tabular}{llll}
\hline $\begin{array}{l}\text { No } \\
\text { Yes }\end{array}$ & 0 & 1 & [Reference] \\
$\begin{array}{l}\text { Reduction of platelet count (percent) } \\
<25\end{array}$ & 3 & 16.5 & $(1.8-150.5)$ \\
$\geqq 25$ & 0 & 1 & {$[$ Reference] } \\
Age (years) & 3 & 14.9 & $(3.4-65.2)$ \\
$<75$ & 0 & 1 & {$[$ Reference] } \\
$\geqq 75$ & 2 & 11.6 & $2.5-53.9$ \\
$\begin{array}{l}\text { Uncommon etiology of perforation } \\
\text { No (diverticulitis, cancer) }\end{array}$ & 0 & 1 & {$[$ Reference] } \\
Yes & 1 & 4.0 & $(1.1-14.2)$ \\
Albumin (<g/dL) & & & \\
$>2.5$ & 0 & 1 & {$[$ Reference $]$} \\
$\leqq 2.5$ & 1 & 3.4 & $(1.0-12.0)$ \\
\hline
\end{tabular}

95\% CI 95\% confidential interval

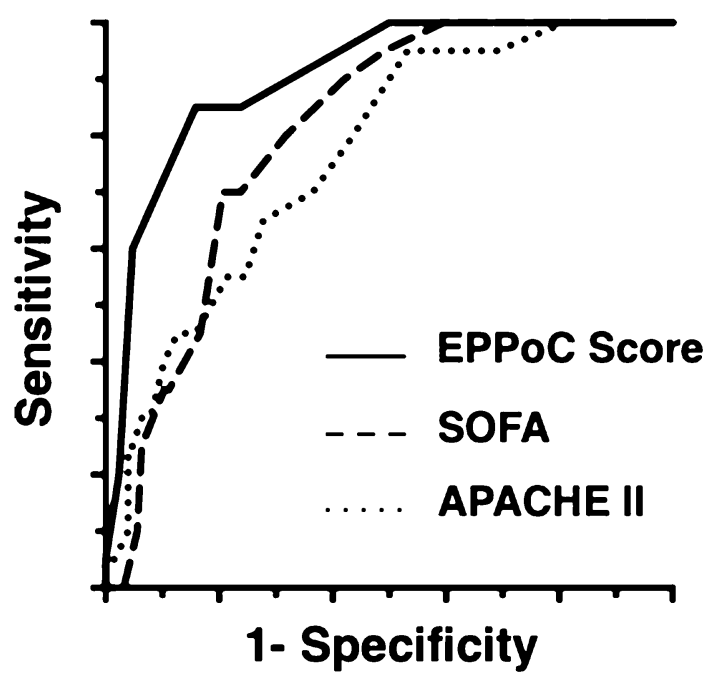

Fig. 2 Receiver operating characteristic (ROC) curves are shown for predicting mortality using the Early Prediction for Prognosis of Colorectal perforation (EPPoC) score, sequential organ failure assessment (SOFA) Score, and acute physiology and chronic health evaluation (APACHE) II Score. The areas under the curve were 0.911, 0.803, and 0.764 for the EPPoC score, SOFA score, and APACHE II score, respectively

system is proposed using these five prognostic factors which has a high discrimination power for mortality prediction and high NPV for classifying the patients with at high-risk for mortality.

A relationship between the etiology of perforation and the prognosis has been reported [2, 3, 11, 12]. Sartelli et al. pointed out that the prognosis of patients with a perforation due to diverticulitis was relatively better compared to patients with perforations due to other causes [11]. Although colon cancer and ischemic disease were grouped together as non-diverticulitis in that study, we divided the other etiologies into colon cancer, which was the second most common etiology, and other uncommon etiologies such as ischemia in the present study. As a result, diverticulitis and colon cancer are not associated with a poor prognosis and "other etiologies" was selected as an independent predictor of mortality. Older age, hypoalbuminemia and hemodialysis, which were previously reported as independent risk factors in gastrointestinal surgery, were also identified as independent predictors of mortality in the present study [13-17]. It is novel and notable that a decrease in the platelet count for a short time in the perioperative period was an independent factor to predict mortality. Although a decrease in the platelet count might be related to dilution by perioperative fluid administration, we think that it may be related to the development of coagulopathy and the severity of the systemic inflammatory response to sepsis, which could have an impact on mortality. As several studies reported that coagulopathy was closely linked to a poor prognosis in patients with sepsis including colorectal perforation [6-10], these results may reflect the early detection of postoperative deterioration in physiologic status, which stands out compared to previous studies.

Another strength of this study is that surgeons can evaluate four of the five predictive factors before operation and remaining factor can be determined immediately after surgery. This suggests that these predictive factors may be useful to guide clinical judgement regarding decisions such as the type of operation or the type of admission (e.g. ICU or general ward), but this requires verification in larger future studies. Several studies report the safety of resection and primary anastomosis in patients with perforated colorectal diverticulitis with peritonitis $[4,5,18]$. However, patients included in these studies suffered from perforated left-sided diverticulitis, which is reported to have a somewhat better prognosis, and often are not critically ill in the preoperative period. In actual clinical practice, where manage patients with colorectal perforation who are hemodynamically unstable or have perforations due to etiologies other than leftsided diverticulitis, we must decide on the optimal procedure or the need for ICU care. In these situations, the predictive factors identified in this study may help surgeons assess the severity of disease and guide the decision-making process.

To forecast the early prognosis of critically ill patients, various scoring systems have been developed [19-24]. However, these scoring systems are based on data obtained after ICU admission or the most abnormal values within $24 \mathrm{~h}$ serving as scoring variables [25-27], and do not consider perioperative parameters that may be more closely related to the prognosis of surgical patients. Moreover, some of these conventional scoring systems need complicated calculations with many variables, including those 
not routinely obtained. The scoring system proposed in this study is derived from perioperative clinical parameters that are easily obtained and developed using data from patients with colorectal perforation. Although the proposed score was derived using a small sample, it demonstrates a high discrimination for mortality and a high NPV for selecting patients with an increased risk of mortality. We believe that this score has the potential to be utilized in clinical practice, and further studies are definitely needed to validate the generalizability of the score.

This study has acknowledged limitations. First, in the present dataset, many patients underwent Hartmann's procedure. The exact procedure performed depended on the institutional policy based on the characteristics of the patients admitted. This might affect the mortality of patients with colorectal perforation. Second, the specific inclusion and exclusion criteria for this clinical situation might be arbitrary and heterogeneous. Patients with micro-perforation or intra-parietal air who failed nonoperative management were not included, because they were operated on more than $24 \mathrm{~h}$ after diagnosis. Finally, the sample size was not sufficient to support development of an accurate risk scoring system. Although we conducted several sensitivity analyses to validate the multivariate logistic model, further study is needed to refine the generalizability of this score.

\section{Conclusion}

Among patient- and disease-related factors determined immediately before and after operation, five perioperative clinical parameters were identified as significantly associated with short-term mortality in patients with colorectal perforation. These five predictors may help surgeon to assess the severity of disease and guide patient management. An easy-to-use scoring system proposed in this study requires future evaluation in large-scale prospective studies.

Supplementary Information The online version contains supplementary material available at https://doi.org/10.1007/s00068-021-01719-8.

Acknowledgements Our thanks are extended to Ryo Takemura, and Ryota Ishii at the division of biostatistics, Keio Clinical and Translational Research Center for statistical analysis.

\footnotetext{
Author contributions TM contributed to this manuscript through study design, data collection, data analysis and interpretation, and manuscript writing. HS contributed to the study design and data interpretation. AL contributed to the data interpretation and critical revisions of the manuscript. KM, RK, RY, KK and JS were involved in study design, data interpretation, and manuscript review. All authors read and approved the final manuscript.
}

Funding No funding was received for conducting this study.
Availability of data and materials The datasets used and/or analyzed during the current study are available from the corresponding author on reasonable request.

\section{Declarations}

Conflicts of interest The authors declare that they have no conflict of interest.

Ethical approval This retrospective study was approved by the Institutional Review Board of Saiseikai Utsunomiya Hospital (No.2020-20).

Consent to participate The requirement for obtaining informed consent from patients was waived, because the data sets were pseudonymous and this study was observational.

\section{References}

1. Cirocchi R, Trastulli S, Desiderio J, Listorti C, Boselli C, Parisi A, et al. Treatment of Hinchey stage III-IV diverticulitis: a systematic review and meta-analysis. Int J Colorectal Dis. 2013;28:447-57.

2. Yamamoto T, Kita R, Masui H, Kinoshita H, Sakamoto Y, Okada $\mathrm{K}$, et al. Prediction of mortality in patients with colorectal perforation based on routinely available parameters: a retrospective study. World J Emerg Surg. 2015;10:24.

3. Biondo S, Ramos E, Deiros M, Rague JM, De Oca J, Moreno P, et al. Prognostic factors for mortality in left colonic peritonitis: a new scoring system. J Am Coll Surg. 2000;191:635-42.

4. Lambrichts DPV, Vennix S, Musters GD, Mulder IM, Swank HA, Hoofwijk AGM, et al. Hartmann's procedure versus sigmoidectomy with primary anastomosis for perforated diverticulitis with purulent or faecal peritonitis (LADIES): a multicentre, parallelgroup, randomised, open-label, superiority trial. Lancet Gastroenterol Hepatol. 2019;4:599-610.

5. Oberkofler CE, Rickenbacher A, Raptis DA, Lehmann K, Villiger $\mathrm{P}$, Buchli $\mathrm{C}$, et al. A multicenter randomized clinical trial of primary anastomosis or Hartmann's procedure for perforated left colonic diverticulitis with purulent or fecal peritonitis. Ann Surg. 2012;256:819-26 (Discussion 26-27).

6. Lyons PG, Micek ST, Hampton N, Kollef MH. Sepsis-associated coagulopathy severity predicts hospital mortality. Crit Care Med. 2018;46:736-42.

7. Iba T, Levy JH, Raj A, Warkentin TE. Advance in the management of sepsis-induced coagulopathy and disseminated intravascular coagulation. J Clin Med. 2019;8:728.

8. Vincent JL, Francois B, Zabolotskikh I, Daga MK, Lascarrou JB, Kirov MY, et al. Effect of a recombinant human soluble thrombomodulin on mortality in patients with sepsis-associated coagulopathy: the SCARLET randomized clinical trial. JAMA. 2019;321:1993-2002.

9. Ordonez CA, Sanchez AI, Pineda JA, Badiel M, Mesa R, Cardona $\mathrm{U}$, et al. Deferred primary anastomosis versus diversion in patients with severe secondary peritonitis managed with staged laparotomies. World J Surg. 2010;34:169-76.

10. Sartelli M, Catena F, Ansaloni L, Coccolini F, Griffiths EA, AbuZidan FM, et al. WSES Guidelines for the management of acute left sided colonic diverticulitis in the emergency setting. World J Emerg Surg. 2016;11:37.

11. Sartelli M, Catena F, Ansaloni L, Coccolini F, Corbella D, Moore $\mathrm{EE}$, et al. Complicated intra-abdominal infections worldwide: 
the definitive data of the CIAOW Study. World J Emerg Surg. 2014;9:37.

12. Espinosa J, Sharma R, Lucerna A, Stranges D. Medical approach to right colon diverticulitis with perforation. Case Rep Emerg Med. 2017;2017:2563218.

13. Shinkawa H, Yasuhara H, Naka S, Yanagie H, Nojiri T, Furuya $\mathrm{Y}$, et al. Factors affecting the early mortality of patients with nontraumatic colorectal perforation. Surg Today. 2003;33:13-7.

14. Alvarez JA, Baldonedo RF, Bear IG, Otero J, Pire G, Alvarez P, et al. Outcome and prognostic factors of morbidity and mortality in perforated sigmoid diverticulitis. Int Surg. 2009;94:240-8.

15. Kriwanek S, Armbruster C, Beckerhinn P, Dittrich K. Prognostic factors for survival in colonic perforation. Int J Colorectal Dis. 1994;9:158-62.

16. Hennessey DB, Burke JP, Ni-Dhonochu T, Shields C, Winter DC, Mealy K. Preoperative hypoalbuminemia is an independent risk factor for the development of surgical site infection following gastrointestinal surgery: a multi-institutional study. Ann Surg. 2010;252:325-9.

17. Masoomi H, Kang CY, Chen A, Mills S, Dolich MO, Carmichael JC, et al. Predictive factors of in-hospital mortality in colon and rectal surgery. J Am Coll Surg. 2012;215:255-61.

18. Lambrichts DP, Edomskis PP, van der Bogt RD, Kleinrensink GJ, Bemelman WA, Lange JF. Sigmoid resection with primary anastomosis versus the Hartmann's procedure for perforated diverticulitis with purulent or fecal peritonitis: a systematic review and meta-analysis. Int J Colorectal Dis. 2020;35:1371.
19. Ochiai T, Hiranuma S, Takiguchi N, Ito K, Kawaguchi A, Iwai T, et al. SOFA Score predicts postoperative outcome of patients with colorectal perforation. Hepatogastroenterology. 2004;51:1007-10.

20. Sugimoto K, Sato K, Maekawa H, Sakurada M, Orita H, Ito T, et al. Analysis of the efficacy of direct hemoperfusion with polymyxin B-immobilized fiber (PMX-DHP) according to the prognostic factors in patients with colorectal perforation. Surg Today. 2013;43:1031-8.

21. Chatterjee AS, Renganathan DN. POSSUM: a scoring system for perforative peritonitis. J Clin Diagn Res. 2015;9:PC05-9.

22. Ishizuka M, Nagata H, Takagi K, Horie T, Kubota K. POSSUM is an optimal system for predicting mortality due to colorectal perforation. Hepatogastroenterology. 2008;55:430-3.

23. Horiuchi A, Watanabe Y, Doi T, Sato K, Yukumi S, Yoshida $\mathrm{M}$, et al. Evaluation of prognostic factors and scoring system in colonic perforation. WJG. 2007;13:3228-31.

24. Billing A, Frohlich D, Schildberg FW. Prediction of outcome using the Mannheim peritonitis index in 2003 patients. Peritonitis Study Group Br J Surg. 1994;81:209-13.

25. Breslow MJ, Badawi O. Severity scoring in the critically ill: part 1 -interpretation and accuracy of outcome prediction scoring systems. Chest. 2012;141:245-52.

26. Le Gall JR. The use of severity scores in the intensive care unit. Intensive Care Med. 2005;31:1618-23.

27. Vincent JL, Moreno R. Clinical review: scoring systems in the critically ill. Crit Care. 2010;14:207. 